\title{
Neutrophil to lymphocyte ratio and platelet to lymphocyte ratio are superior to other inflammation-based prognostic scores in predicting the mortality of patients with gastrointestinal perforation
}

\author{
Yuichiro Shimoyama ${ }^{1 *}$, Osamu Umegaki ${ }^{1}$, Tomoyuki Agui ${ }^{2}$, Noriko Kadono ${ }^{1}$ and Toshiaki Minami ${ }^{3}$
}

\begin{abstract}
Background: The neutrophil to lymphocyte ratio (NLR) is gaining interest as an independent predictor of survival in patients with various clinical conditions. No study to date has reported an association between inflammationbased prognostic scores, including the Glasgow Prognostic Score (GPS), NLR, platelet to lymphocyte ratio (PLR), Prognostic Nutritional Index (PNI), and Prognostic Index (PI), and mortality in patients with gastrointestinal perforation (GIP). We compared the prognostic value of these measures.

Findings: A total of 32 patients with GIP were retrospectively enrolled. Patients were assessed according to the GPS, NLR, PLR, PI, and PNI. Multivariate analyses were performed to identify variables associated with mortality. Receiver operating characteristic (ROC) analyses were also performed. Overall survival rates (in-hospital mortality) were calculated using the Kaplan-Meier method, and differences in survival rates between groups were compared by the log-rank test. Multivariate analysis of significant variables revealed NLR (HR 1.257, 95\% Cl 1.035-1.527, $P=0.021)$ and PLR (HR 1.004, 95\% Cl 1.001-1.007, $P=0.016)$ at the time of admission to the intensive care unit to be independently associated with in-hospital mortality. AUC analysis revealed Sequential Organ Failure Assessment-Glasgow Coma Scale (SOFA-GCS) (0.73) to be superior to NLR (0.57) and PLR (0.58) for predicting mortality, and a high SOFA-GCS score was associated with reduced overall survival $(P<0.05)$.
\end{abstract}

Conclusions: NLR and PLR were superior to other inflammation-based prognostic scores in predicting the mortality of patients with GIP.

Keywords: Inflammation-based prognostic score, Gastrointestinal perforation, In-hospital mortality

\section{Findings}

\section{Introduction}

The neutrophil to lymphocyte ratio (NLR) has gained interest as an independent predictor of survival in patients with various clinical conditions, ranging from oncological to cardiovascular diseases. NLR has also been reported to predict bacteremia better than other infection markers [1],

\footnotetext{
* Correspondence: shimocchiliebesfreud512@yahoo.co.jp

'Department of Anesthesiology, Osaka Medical College, Intensive Care Unit, Osaka Medical College Hospital, 2-7 Daigaku-machi, Takatsuki, Osaka 569-8686, Japan

Full list of author information is available at the end of the article
}

and an NLR $>7$ was reportedly an independent marker of mortality in patients with bacteremia [2].

Gastrointestinal perforation (GIP) is a life-threatening disease with a high mortality rate; GIP often leads to shock and usually requires active rescue in the intensive care unit (ICU) and emergency laparotomy [3]. No previous study has reported an association between inflammation-based prognostic scores and outcomes in patients with GIP.

We hypothesized that NLR measured at the time of admission to the ICU may better predict in-hospital mortality 
in patients with GIP, as compared with other inflammationbased prognostic scores. To test this hypothesis, we compared the prognostic value of various inflammation-based prognostic scores in patients with GIP.

\section{Methods}

We conducted a single-center retrospective study in a 16-bed ICU. The study protocol was approved by the Ethics Committee of Osaka Medical College (Osaka, Japan). A total of 40 patients diagnosed with GIP, who underwent surgery and were treated in the ICU of Osaka Medical College Hospital between January 2014 and June 2016, were retrospectively enrolled. Of these, 32 patients were evaluated, excluding those who were aged 18 years or younger; who were pregnant; who had immunosuppressive disease (e.g., HIV), or were undergoing immunosuppressive therapy (e.g., chemotherapy, chronic use of steroids, autoimmune disease treatment) within 1 month of the study; and who had cardiac arrest at the time of ICU admission. Individual patient consent was not obtained since all data used in this study were acquired retrospectively from the laboratory information system without any additional blood sampling or laboratory analysis. The main outcome measure was inhospital mortality. The following demographic and clinical data were collected: age, sex, comorbidities (cancer, coronary artery disease, diabetes mellitus, hypertension, and renal disease), Sequential Organ Failure Assessment-Glasgow Coma Scale (SOFA-GCS) score at ICU day 1, length of hospital stay, and in-hospital mortality. Since our study population included intubated

Table 1 Inflammation-based prognostic scores

\begin{tabular}{ll}
\hline Scoring systems & Score \\
\hline Glasgow Prognostic Score & \\
CRP $\left(\leq 10 \mathrm{~m} \mathrm{I}^{-1}\right)$ and albumin $\left(\geq 35 \mathrm{~g} \mathrm{I}^{-1}\right)$ & 1 \\
CRP $\left(\leq 10 \mathrm{~m} \mathrm{I}^{-1}\right)$ and albumin $\left(<35 \mathrm{~g} \mathrm{I}^{-1}\right)$ & 1 \\
CRP $\left(>10 \mathrm{~m} \mathrm{I}^{-1}\right)$ and albumin $\left(\geq 35 \mathrm{~g} \mathrm{I}^{-1}\right)$ & 2 \\
CRP $\left(>10 \mathrm{mg} \mathrm{I}^{-1}\right)$ and albumin $\left(<35 \mathrm{~g} \mathrm{I}^{-1}\right)$ & \\
Neutrophil to lymphocyte ratio & \\
Neutrophil count: lymphocyte count & \\
Plt to lymphocyte ratio & \\
Plt count: lymphocyte count & \\
Prognostic Index & \\
CRP $\left(\leq 10 \mathrm{mg} \mathrm{I}^{-1}\right)$ and white blood cell count $\left(\leq 11 \times 10^{9} \mathrm{I}^{-1}\right)$ & 0 \\
CRP $\left(\leq 10 \mathrm{mg} \mathrm{I}^{-1}\right)$ and white blood cell count $\left(>11 \times 10^{9} \mathrm{I}^{-1}\right)$ & 1 \\
CRP $\left(>10 \mathrm{mg} \mathrm{I}^{-1}\right)$ and white blood cell count $\left(\leq 11 \times 10^{9} \mathrm{I}^{-1}\right)$ & 1 \\
CRP $\left(>10 \mathrm{mg} \mathrm{I}^{-1}\right)$ and white blood cell count $\left(>11 \times 10^{9} \mathrm{I}^{-1}\right)$ & 2 \\
Prognostic Nutritional Index & \\
Albumin $\left(\mathrm{g} \mathrm{I}^{-1}\right)+5 \times$ total lymphocyte count $10^{9} \mathrm{I}^{-1}$ & \\
\hline CRP C- &
\end{tabular}

CRP C-reactive protein, Plt platelet patients under sedation with propofol and/or dexmedetomidine at ICU admission, we excluded the GCS item from the SOFA score. Blood samples were obtained upon ICU admission for measurements of CRP, albumin, white blood cell count, neutrophil count, lymphocyte count, and platelet count. The GPS, NLR, PLR, PI, and PNI were obtained as shown in Table 1.

Descriptive analysis was performed for all variables. Continuous variables were expressed as median (interquartile range), and categorical variables as counts (percentage). Patient characteristics were compared between survivors and non-survivors using Fischer's exact test. Univariate analysis and multivariate analysis (Cox proportional hazards model) were used to examine associations between patient characteristics and prognostic factors. Analyses using Cox proportional hazards models were performed by forward selection of variables which were found to be significant by univariate analysis and inflammation-based prognostic scores. Receiver operating characteristics (ROC) curves were generated for variables which were significant in the multivariate analysis, and areas under the curve (AUCs), cutoff values, sensitivities, specificities, and predictive values were calculated. Using these cutoff values, overall survival rates (in-hospital mortality) were calculated with the KaplanMeier method, and differences in survival rates between groups were compared by the log-rank test. A $P$ value <

Table 2 Patient demographics

\begin{tabular}{|c|c|c|c|}
\hline \multirow[b]{2}{*}{ Variables } & \multicolumn{2}{|l|}{ All patients } & \multirow{2}{*}{$\begin{array}{l}\text { Univariate } \\
\text { analysis } \\
P \text { value }\end{array}$} \\
\hline & $\begin{array}{l}\text { Survivors } \\
(n=24)\end{array}$ & $\begin{array}{l}\text { Non-survivors } \\
(n=8)\end{array}$ & \\
\hline Age, year & $74(65.5-79)$ & $66.5(64.5-73)$ & 0.58 \\
\hline Female & $14(58.3)$ & $4(50)$ & 0.62 \\
\hline Male & $10(41.7)$ & $4(50)$ & \\
\hline Cancer & $16(67)$ & $6(75)$ & 0.69 \\
\hline CAD & 1 & 0 & \\
\hline Diabetes & 4 & 0 & \\
\hline Hypertension & 8 & 0 & \\
\hline Renal disease & $1(4)$ & $3(38)$ & 0.039 \\
\hline Observation period & $36(24-46.5)$ & $20.5(13.8-25.8)$ & 0.0069 \\
\hline Albumin $\left(\mathrm{g}^{-1}\right)$ & $19(14.8-24)$ & $23(13.8-28.3)$ & 0.406 \\
\hline $\mathrm{CRP}\left(\mathrm{mg} \mathrm{I}^{-1}\right)$ & $11.5(8.3-18)$ & $9.1(5.4-15)$ & 0.809 \\
\hline WBC $\left(\times\left. 10^{9}\right|^{-1}\right)$ & $6.3(3.6-8.4)$ & $4.8(3.8-6.8)$ & 0.552 \\
\hline $\begin{array}{l}\text { Neutrophil count } \\
\left(\times 10^{9} \mathrm{I}^{-1}\right)\end{array}$ & $5.3(2.9-7.2)$ & $3.8(3.2-4.9)$ & 0.454 \\
\hline $\begin{array}{l}\text { Lymphocyte count } \\
\left(\times 10^{9} \mathrm{I}^{-1}\right)\end{array}$ & $0.49(0.36-0.78)$ & $0.31(0.28-0.37)$ & 0.064 \\
\hline Plt count $\left(\times 10^{4} \mathrm{~mm}^{-3}\right)$ & $17.3(15.2-23.2)$ & $21.1(8.0-29)$ & 0.484 \\
\hline
\end{tabular}

CAD coronary artery disease, CRP C-reactive protein, WBC white blood cell, Plt platelet 
Table 3 Inflammation-based prognostic scores

\begin{tabular}{llll}
\hline & All patients & & $\begin{array}{l}\text { Univariate } \\
\text { analysis }\end{array}$ \\
Variables & $\begin{array}{l}\text { Survivors } \\
(n=24)\end{array}$ & $\begin{array}{l}\text { Non-survivors } \\
(n=8)\end{array}$ & \\
\hline $\begin{array}{l}\text { SOFA-GCS score at } \\
\text { ICU admission }\end{array}$ & $3(2-4.25)$ & $6.5(4.8-8.3)$ & 0.0087 \\
GPS (0/1/2) & $(0 / 8 / 16)$ & $(0 / 5 / 3)$ & 0.161 \\
NLR & $8.7(6.4-14.9)$ & $13.7(7.7-15.6)$ & 0.432 \\
PLR & $390.2(279.8-688.5)$ & $596.2(274.8-783.8)$ & 0.057 \\
PI (0/1/2) & $(8 / 12 / 4)$ & $(4 / 4 / 0)$ & 0.262 \\
PNI & $20.6(17.4-25.8)$ & $24.3(15.4-29.8)$ & 0.611 \\
\hline SOFA Sequen
\end{tabular}

SOFA Sequential Organ Failure Assessment, GCS Glasgow Coma Scale, ICU intensive care unit, GPS Glasgow Prognostic Score, NLR neutrophil to lymphocyte ratio, PLR platelet to lymphocyte ratio, PI Prognostic Index, PNI Prognostic Nutritional Index

0.05 was considered statistically significant. All statistical analyses were performed using the BellCurve for Excel software package v.2.0 (Social Survey Research Information Co., Ltd., Tokyo, Japan).

\section{Results}

Baseline characteristics of the patients are shown in Tables 2 and 3. Twenty-four (75\%) patients were survivors (perforation in the colon, 16; small intestine, 6; stomach, 1 ; appendix, 1), and 8 (25\%) were non-survivors (colon, 4; small intestine, 4). The median age was 74 (range, 65.579) years for survivors and 66.5 (range, 64.5-73) years for non-survivors. Among survivors, 10 (41.7\%) patients were males and 14 (58.3\%) were females, and among nonsurvivors, 4 (50\%) were males and 4 (50\%) were females.

Multivariate Cox proportional hazards models revealed NLR (HR 1.257, 95\% CI 1.035-1.527, $P=0.021$ ) and PLR (HR 1.004, 95\% CI 1.001-1.007, $P=0.016$ ) to be independently associated with in-hospital mortality (Table 4). Cutoff values for mortality obtained from ROC analysis (Fig. 1) were 13.28 (sensitivity, 62.5\%; specificity, 66.7\%; area under the curve (AUC), 0.57; 95\% CI, 0.31-0.83; $P=0.607$ ) for NLR and 590.44 (sensitivity, 62.5\%; specificity, 66.7\%; AUC, 0.58; 95\% CI, 0.33-0.84; $P=0.521$ ) for PLR (Tables 5 and 6). AUC analyses revealed SOFA-GCS (0.73) to be superior to NLR (0.57) and PLR (0.58) for predicting mortality

Table 4 Predictors of mortality by multivariate analysis

\begin{tabular}{llll}
\hline Predictors & Hazard ratio & $95 \% \mathrm{Cl}$ & $P$ value \\
\hline SOFA-GCS score & 1.709 & $1.108-2.637$ & 0.015 \\
NLR & 1.257 & $1.035-1.527$ & 0.021 \\
PLR & 1.004 & $1.001-1.007$ & 0.016 \\
Renal disease & 1.238 & $0.13-11.821$ & 0.853
\end{tabular}

SOFA Sequential Organ Failure Assessment, GCS Glasgow Coma Scale, NLR neutrophil to lymphocyte ratio, $P L R$ platelet to lymphocyte ratio

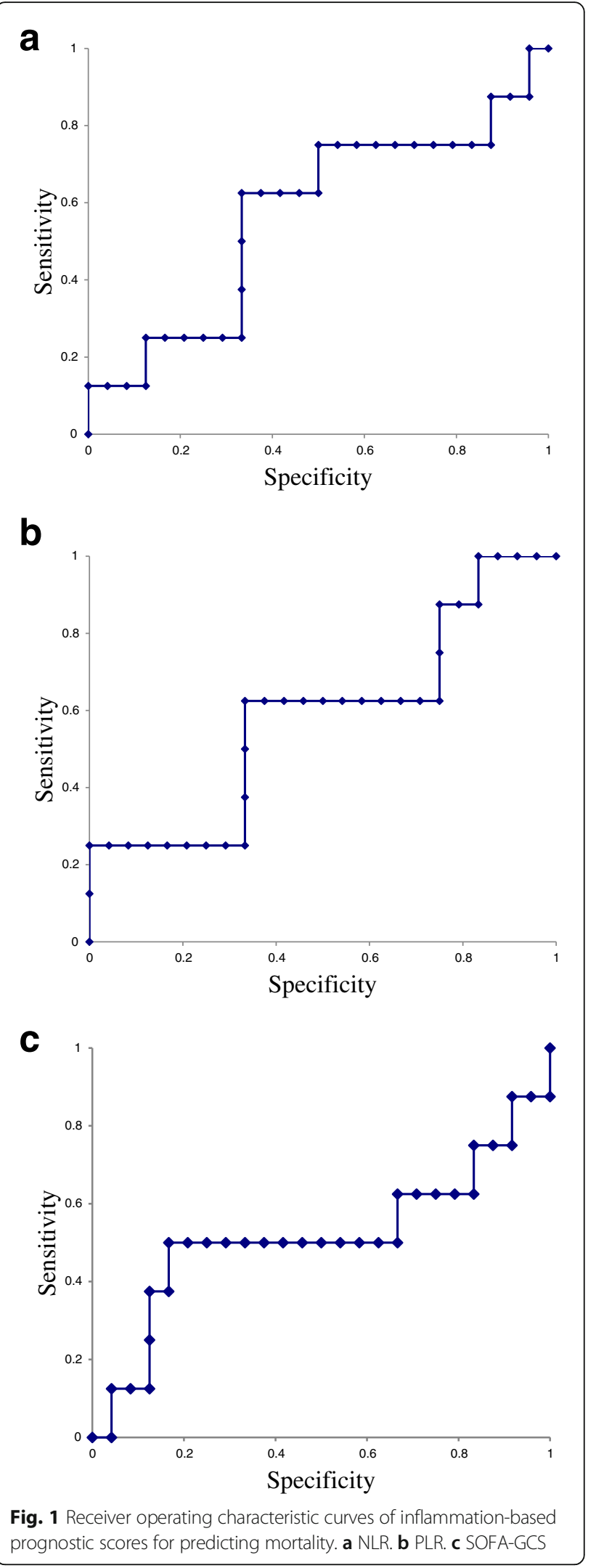

Fig. 1 Receiver operating characteristic curves of inflammation-based
prognostic scores for predicting mortality. a NLR. b PLR. c SOFA-GCS 
Table 5 Performance parameters for predictors of mortality

\begin{tabular}{llllll}
\hline Predictors & $\begin{array}{l}\text { Cutoff } \\
\text { value }\end{array}$ & $\begin{array}{l}\text { Sensitivity } \\
(\%)\end{array}$ & $\begin{array}{l}\text { Specificity } \\
(\%)\end{array}$ & $\begin{array}{l}\text { PPV } \\
(\%)\end{array}$ & $\begin{array}{l}\text { NPV } \\
(\%)\end{array}$ \\
\hline SOFA- & 6 & 75 & 87.5 & 66.7 & 91.3 \\
GCS & & & & & \\
NLR & 13.28 & 62.5 & 66.7 & 38.5 & 84.2 \\
PLR & 590.44 & 62.5 & 66.7 & 38.5 & 84.2
\end{tabular}

PPV positive predictive value, NPV negative predictive value, SOFA Sequential Organ Failure Assessment, GCS Glasgow Coma Scale, NLR neutrophil to lymphocyte ratio, $P L R$ platelet to lymphocyte ratio

(Table 6). A high SOFA-GCS score was associated with reduced overall survival $(P<0.05)$ (Fig. 2).

\section{Discussion}

NLR and PLR were found to be superior to other inflammation-based prognostic scores in predicting the mortality of patients with GIP. NLR and PLR are based primarily on the physiological link between neutrophilia and lymphopenia with systemic inflammation. Jilma et al. [4] studied changes in white blood cell types after inflammation and reported a $300 \%$ increase in circulating neutrophils, 96\% decrease in monocytes, and $85 \%$ decrease in lymphocytes 4 to $6 \mathrm{~h}$ after inflammation. Below, we discuss the literature surrounding NLR and the prognostic capabilities of NLR for GIP.

Growing evidence suggests the usefulness of NLR in the prediction of survival in various contexts, such as lung cancer, colorectal cancer, orthotopic liver transplantation for primary hepatocellular carcinoma, postoperative coronary artery bypass grafting, chronic heart failure, pulmonary emboli, and acute pancreatitis $[1,5,6]$. Moreover, NLR was a more sensitive parameter than increased white blood cell count in patients with suspected appendicitis [7]. These data suggest the importance of NLR in multiple patient populations.

In the present study, NLR and PLR had a positive predictive value of $38.5 \%$ and a negative predictive value of $84.2 \%$, suggesting that NLR and PLR may be more useful for ruling out mortality, rather than predicting it. NLR and PLR can be obtained easily, cheaply, and rapidly and can provide relevant information for necessary interventions within the first few hours of hospital admission. As discussed earlier, studies have shown that NLR predicts bacteremia better than other infection

Table 6 Comparison of AUC between predictors

\begin{tabular}{llll}
\hline Predictors & AUC & $95 \% \mathrm{Cl}$ & $P$ value \\
\hline SOFA-GCS & 0.73 & $0.44-1.02$ & 0.112 \\
NLR & 0.57 & $0.31-0.83$ & 0.607 \\
PLR & 0.58 & $0.33-0.84$ & 0.521 \\
\hline
\end{tabular}

AUC area under the curve, SOFA Sequential Organ Failure Assessment, GCS Glasgow Coma Scale, NLR neutrophil to lymphocyte ratio, PLR platelet to lymphocyte ratio

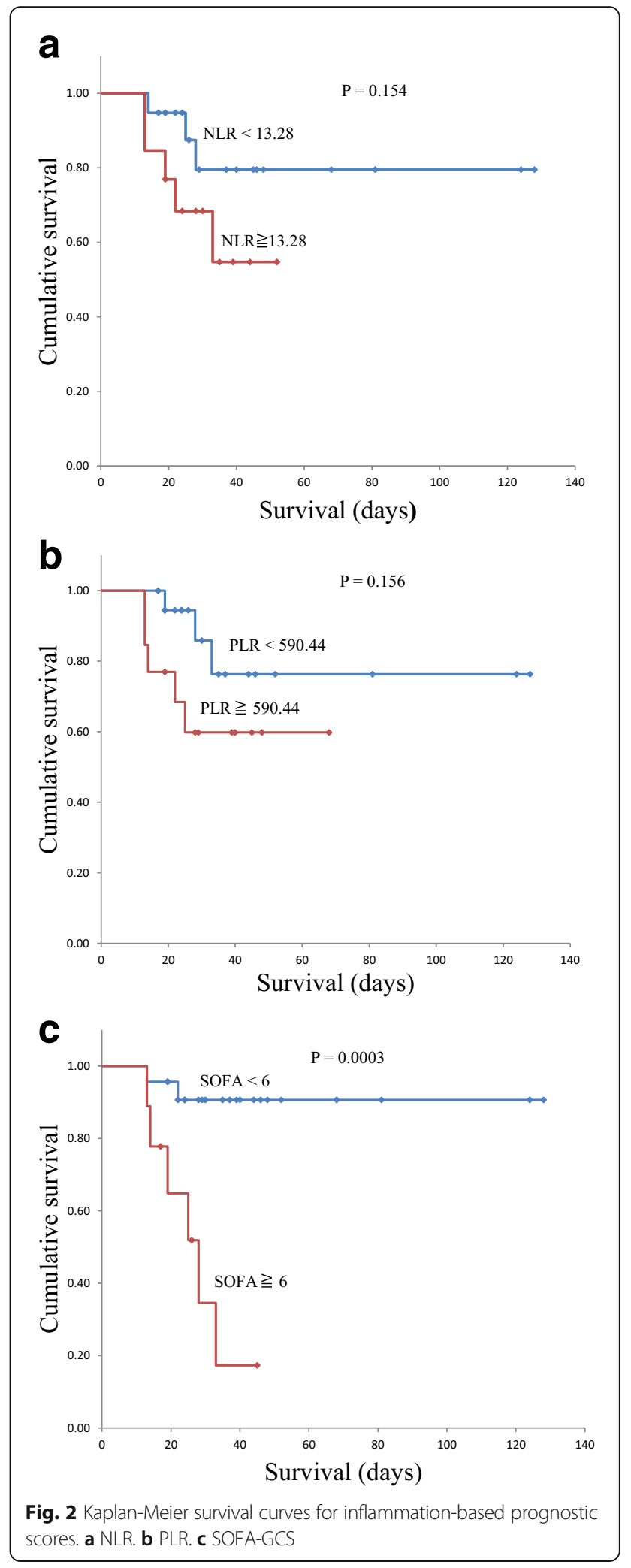

markers [1] and an NLR $>7$ was reportedly an independent predictor of mortality in patients with bacteremia [2]. In another study, the initial NLR 
measured at ED admission was independently associated with 28-day mortality in patients with severe sepsis and septic shock [8]. However, these previous studies did not assess associations between inflammation-based prognostic scores, including the GPS, NLR, PLR, PNI, and PI, and mortality in patients with GIP. Our results are informative in this respect.

This study has a potential limitation. Given the retrospective, single-center design of the study and small cohort, multivariate analysis may be difficult to apply. A large-scale prospective validation study will be needed to confirm our results.

\section{Conclusion}

NLR and PLR were superior to other inflammationbased prognostic scores in predicting the mortality of patients with GIP.

\begin{abstract}
Abbreviations
AUC: Area under the curve; CRP: C-reactive protein; GCS: Glasgow Coma Scale; GIP: Gastrointestinal perforation; GPS: Glasgow Prognostic Score; ICU: Intensive care unit; NLR: Neutrophil to lymphocyte ratio; PI: Prognostic Index; PLR: Platelet to lymphocyte ratio; PNI: Prognostic Nutritional Index; ROC: Receiver operating characteristics; SOFA: Sequential Organ Failure Assessment
\end{abstract}

\section{Acknowledgements}

None.

\section{Funding}

The authors declare that they have no competing sources of funding

\section{Availability of data and materials}

The datasets of the present study are available from the corresponding author upon reasonable request.

\section{Authors' contributions}

YS participated in the study design, collected data, performed the statistical analysis, and drafted the manuscript; OU, TA, NK, and TM participated in the study design and revised the manuscript. All authors read and approved the final manuscript.

\section{Ethics approval and consent to participate}

The study protocol was approved by the Ethics Committee of Osaka Medical College (Osaka, Japan).

\section{Consent for publication}

Not applicable.

\section{Competing interests}

The authors declare that they have no competing interests.

\section{Author details}

'Department of Anesthesiology, Osaka Medical College, Intensive Care Unit, Osaka Medical College Hospital, 2-7 Daigaku-machi, Takatsuki, Osaka 569-8686, Japan. ${ }^{2}$ Department of Surgery, Osaka Medical College, Intensive Care Unit, Osaka Medical College Hospital, Takatsuki, Japan. ${ }^{3}$ Department of Anesthesiology, Osaka Medical College, Takatsuki, Japan.

Received: 24 May 2017 Accepted: 24 August 2017

Published online: 02 September 2017

\section{References}

1. de Jager CP, van Wijk PT, Mathoera RB, de Jongh-Leuvenink J, van der Pol T, Wever PC. Lymphocytopenia and neutrophil-lymphocyte count ratio predict bacteremia better than conventional infection markers in an emergency care unit. Crit Care. 2010;14:R192.

2. Terradas R, Grau S, Blanch J, Riu M, Saballs P, Castells X, et al. Eosinophil count and neutrophil-lymphocyte count ratio as prognostic markers in patients with bacteremia: a retrospective cohort study. PLoS One. 2012;7:e42860.

3. Gao Y, Yu K, Kang K, Liu HT, Zhang X, Huang R, et al. Procalcitionin as a diagnostic marker to distinguish upper and lower gastrointestinal perforation. World J Gastroenterol. 2017;23:4422-7.

4. Jilma B, Blann A, Pernerstorfer T, Stohlawetz P, Eichler HG, Vondrovec B, et al. Regulation of adhesion molecules during human endotoxemia. No acute effects of aspirin. Am J Respir Crit Care Med. 1999:159:857-63.

5. Kayrak M, Erdoğan Hil, Solak Y, Akilli H, Gül EE, Yildirim O, et al. Prognostic value of neutrophil to lymphocyte ratio in patients with acute pulmonary embolism: a retrospective study. Heart Lung Circ. 2014;23:56-62.

6. Azab B, Jaglall N, Atallah JP, Lamet A, Raja-Surya V, Farah B, et al. Neutrophil-lymphocyte ratio as a predictor of adverse outcomes of acute pancreatitis. Pancreatology. 2011;11:445-52.

7. Goodman DA, Goodman CB, Monk JS. Use of the neutrophil: lymphocyte ratio in the diagnosis of appendicitis. Am Surg. 1995;61:257-9.

8. Hwang SY, Shin TG, Jo IJ, Jeon K, Suh GY, Lee TR, et al. Neutrophil-tolymphocyte ratio as a prognostic marker in critically-ill septic patients. Am J Emerg Med. 2017:35:234-9.

\section{Submit your manuscript to a SpringerOpen ${ }^{\circ}$ journal and benefit from:}

- Convenient online submission

- Rigorous peer review

- Open access: articles freely available online

- High visibility within the field

Retaining the copyright to your article

Submit your next manuscript at $\boldsymbol{s p r i n g e r o p e n . c o m ~}$ 